\title{
Improving Climate Change Literacy and Promoting Outreach in an Undergraduate Atmospheric Sciences Program
}

\author{
Janel Hanrahan and Jason Shafer
}

C limate scientists agree that recent global warming can primarily be attributed to human activities and the potential consequences of future climate change are enormous (IPCC 2013; USGCRP 2017). The impacts include species shift and extinction, food and water shortages, sea level rise, ever-increasing weather variability, and growing climate refugee crises (Parmesan and Yohe 2003; Biermann and Boas 2010; Hansen et al. 2013; Wheeler and von Braun 2013; Urban 2015; Knutti et al. 2016). While mitigation is essential to lessen the extent of these wide-ranging impacts, this issue is not a priority for most Americans (Roser-Renouf et al. 2016). Many do not understand that humans are causing climate change or that there is agreement among experts (Leiserowitz et al. 2018). This well-documented discrepancy between experts and nonexperts can have far-reaching consequences. If humans do not have a clear understanding of their own role in the transformation of our climate system, they cannot construct a meaningful course of action to correct it.

In the Atmospheric Sciences Department at Northern Vermont University-Lyndon (formerly Lyndon State College; hereafter referred to as Lyndon), we are working to improve climate change literacy in two

AFFILIATIONS: HANRAHAN AND SHAFER-Department of Atmospheric Sciences, Northern Vermont University-Lyndon, Lyndonville, Vermont

CORRESPONDING AUTHOR: Janel Hanrahan,

janel.hanrahan@northernvermont.edu

The abstract for this article can be found in this issue, following the table of contents.

DOI:10.1175/BAMS-D-17-0332.I

(C2019 American Meteorological Society

For information regarding reuse of this content and general

copyright information, consult the AMS Copyright Policy. ways. First, we have implemented curricular changes to our B.S. program to increase the number of atmospheric scientists who understand fundamental climate change science. All students in the program, ranging from aspiring National Weather Service forecasters to broadcast meteorologists, are learning about anthropogenic climate change. Second, through curricular and extracurricular changes, we are encouraging these experts to engage with nonexperts and providing them with resources and opportunities to do so.

CURRICULAR CHANGES. In 2015, the Lyndon Atmospheric Sciences (ATM) B.S. core curriculum was modified to include a two-semester climatology course designed for sophomore-level students. The new course expands upon traditional climatology course content which often assumes a steady-state climate system, to include climate change forcing mechanisms over various time scales, ranging from long-term natural changes on a geologic time scale, to recent short-term human-caused changes. Students obtain and analyze recent climate data, using statistical techniques to create quantitative and graphical summaries and to understand changes through time.

Alongside scientific writing and presenting in the classroom, sophomore-level students are now also required to write informal science blogs and to create shareable digital pieces such as infographics and videos. By interweaving formal and informal communication assignments in one course, students can compare and contrast these distinctly different ways of conveying scientific information, helping them to understand how future communication may be appropriately tailored depending on the audience. Some of the informal student-generated content is then highlighted on a department-run website and shared on social media platforms. Examples of student work can be found at www.theclimateconsensus.com. 


\section{EXTRACURRICULAR OPPORTUNITIES.}

Outside the classroom, department faculty and staff are organizing extracurricular opportunities that allow students to participate in climate change outreach efforts through involvement with Lyndon's Climate Consensus Group. The group was formed in 2014 with two primary goals: 1 ) to teach undergraduate students about effective ways to communicate basic climate change science to non-scientists and 2) to foster relationships between scientists and the community to improve public understanding of climate change science. The group meets monthly, where ATM faculty facilitate discussions about the current state of the science and recent skeptical arguments, and to plan upcoming group activities. Importantly, these meetings provide students with opportunities to freely discuss ongoing attempts to communicate climate change concepts, including exchanges with the public during organized group events and informal conversations with family and friends.

Outreach activities have taken many forms, most of which have occurred at middle and high schools. Relationships were quickly established with local educators through email inquiries, and we now regularly receive unsolicited messages from schools around the state who are interested in visits by our group. Most classroom visits are similar in structure, involving 2-4 ATM students who convey the critical messages: Climate change is real, it is caused by humans, and it is serious but solvable (Ding et al. 2011). This is done with a well-rehearsed group-created presentation. Following the presentation, there is an open discussion which may be completed in smaller breakout groups, allowing for audience questions and more informal conversations. Recently, we have been invited to speak to larger groups, ranging in size from 100 to 600 students, in assembly-style gatherings. For these larger events, ATM faculty have taken the lead in presenting, occasionally with the assistance of a student, followed by smaller student-led breakout group discussions.

In addition to nearly a dozen schools, group members have spoken at a green-faith church, organized several on-campus informational events including presentations and movie screenings, attended various environmental events, and more recently, they have become involved in community planning meetings for local climate change initiatives. For the latter, we have been enthusiastically welcomed by community members who are pleasantly surprised to see scientists at their meetings. In addition to education outreach, members of The Climate Consensus group have participated in three climate marches, two local events and one in Washington, D.C.

\section{RESULTS: CHANGING STUDENT MIND-}

SETS. To evaluate the impact of these curricular and extracurricular changes, we invited all ATM students to complete a Google Form survey during spring 2018. This was done anonymously and we achieved a $72 \%$ participation rate ( $n=52$ students). Student respondents were grouped into two categories. The first-year cohort $(n=16)$ represents students who have had little college classroom exposure to climate change concepts, and the upperclassmen cohort (sophomores through seniors; $n=36$ ) represents students who have taken the new sophomore-level course and other climate change-related courses depending on career pathway and personal interest.

Student interest in climate change. Most incoming Lyndon ATM students enter the field because of a longstanding interest in severe weather and/or broadcast meteorology. This is a theme that appears on department surveys and often comes up during conversations with prospective students and their families. Even in recent years, climatology and/or climate change has not surfaced as a primary reason for pursuing an atmospheric sciences degree. To the contrary, a non-trivial number of students have instead expressed disdain for curricular inclusion of climate change-related information.

Results from the present survey support this notion, as only $15 \%$ of our students stated that they somewhat or completely agreed with the statement, "I initially opted to pursue a degree in ATM because I am interested in climatology and/or climate change." However, this number jumped to $61 \%$ among upperclassmen when presented with the statement, "I am currently interested in climatology and/or climate change" (Figs. 1a,b). Furthermore, when asked to complete the statement, "Since entering the ATM program, my interest in climatology and/or climate change has __, $81 \%$ of upperclassmen responded with "increased," and none stated that their level of interest had decreased (Fig. 1c). The latter suggests that the curricular inclusion of climate change does not have a negative effect even in the face of student resistance to the topic at the onset.

When posed with an open-ended question about why their interest in climatology has increased, the vast majority of students stated that this was the 
(a) "I initially opted to pursue a degree in ATM because I am interested in climatology and/or climate change."

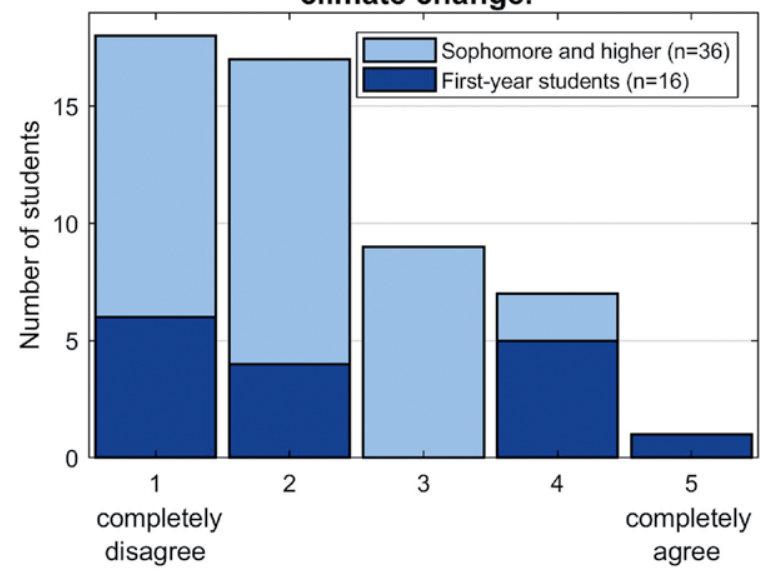

(c) "Since entering the ATM program at NVU-L, my interest in climatology and/or climate

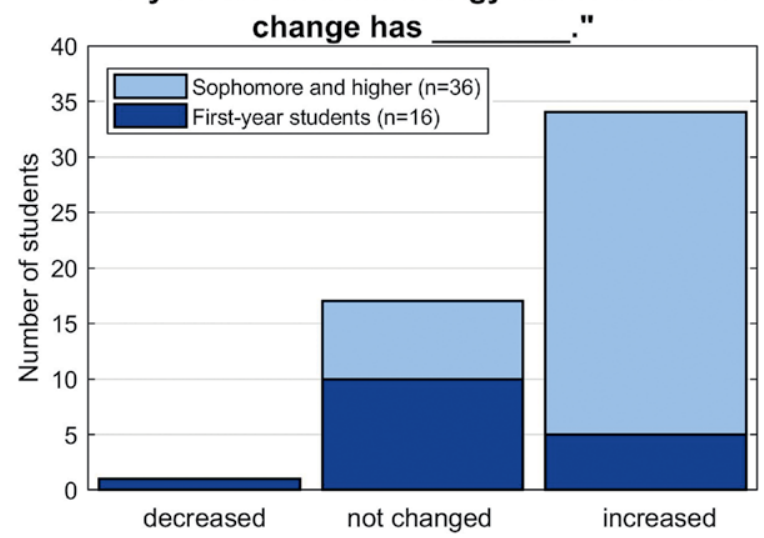

(b) "I am currently interested in climatology and/or climate change"

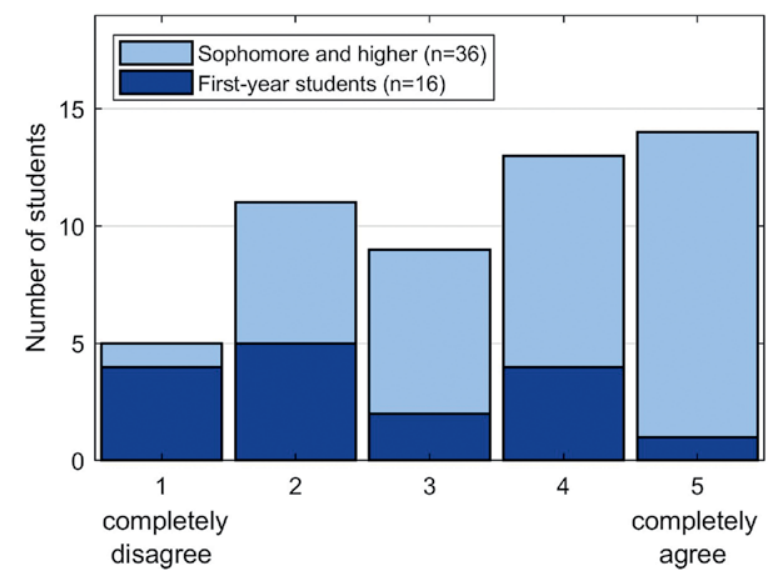

(d) "I think it is important for scientists to communicate the science of global warming to the public"

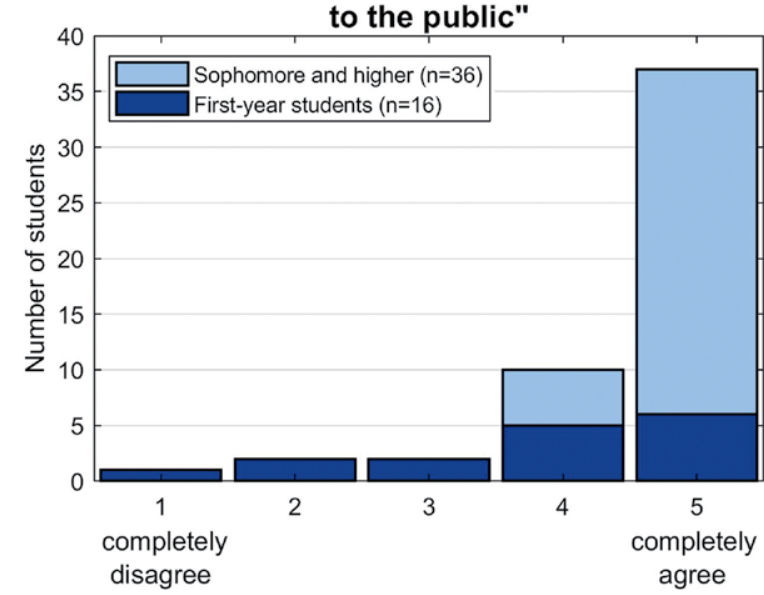

Fig. I. Level of agreement by Lyndon ATM students with statements about (a) initial and (b) current interest in climatology and/or climate change, (c) whether this has increased or decreased, and (d) level of agreement about the importance of climate change communication. Dark blue indicates first-year students, and light blue indicates all other students (sophomore and higher). Results obtained from an anonymous online survey distributed in spring 2018.

direct result of classroom learning. Some of the responses to this question were as follows:

“...the sophomore-year curriculum really sparked my interest."

"The courses made me realize how little I actually knew about climate change... It was truly eye-opening."

“It has definitely increased since coming to Lyndon...It wasn't talked about in my high school...”

“...prior to coming here, I really didn't know anything about climate change. I had heard so many conflicting things about it in the media and came from a family that did not believe anthropogenic climate change was real."

\footnotetext{
"There is much more talk surrounding the subject at Lyndon compared to back home."
}

Anecdotally, we have observed a higher level of interest in climate change among students over the past few years. This is evident in a shift in academic pathways, as more students have been selecting independent projects, internships, and career paths with connections to climate change. 
(a)

Before entering ATM, how often did you discuss global warming with family and friends?

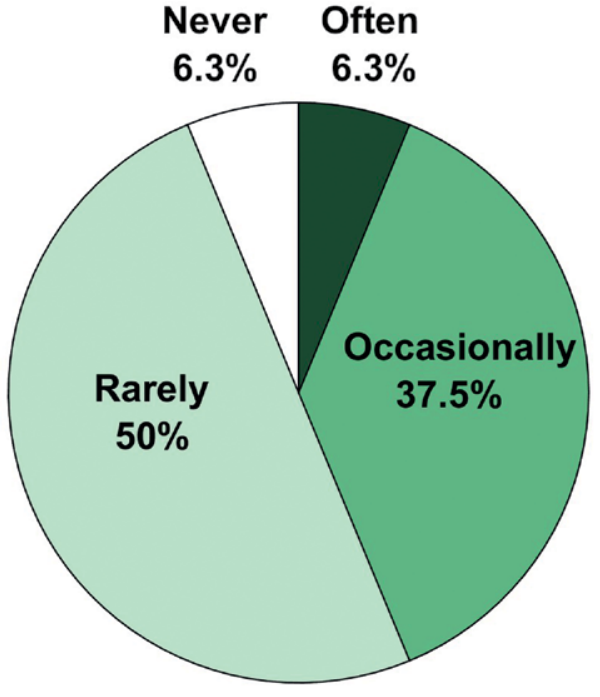

First-year students $(n=16)$

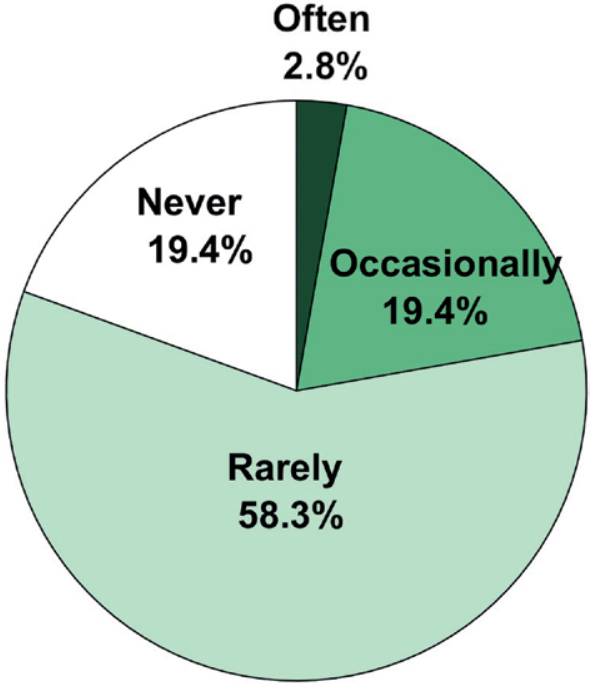

Sophomore and higher $(n=36)$

(b)

At the present time, how often do you discuss global warming with others outside of the ATM department?

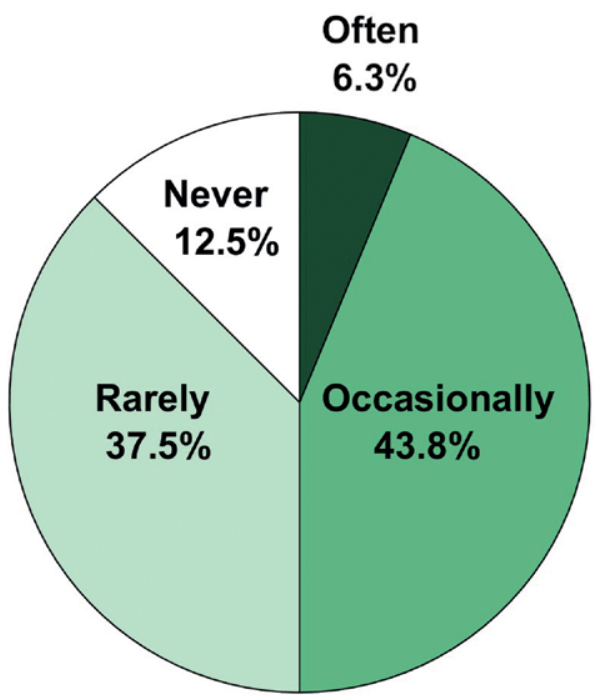

First-year students $(\mathrm{n}=16)$

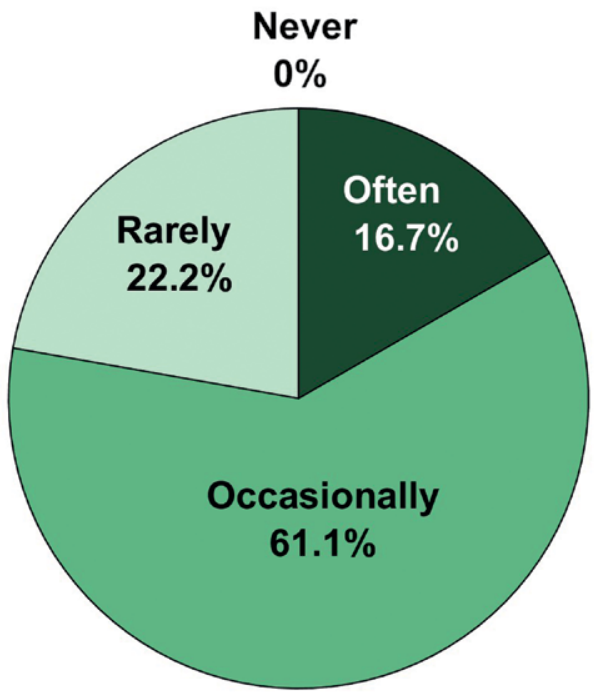

Sophomore and higher $(n=36)$

FIG. 2. Extent of discussion about global warming with family and friends (a) before entering the ATM program at Lyndon and (b) at the present time. Results are for (left) first-year students and (right) all other students (sophomore and higher). Results obtained from an anonymous online survey distributed in spring 2018. 
Student engagement with the general public. We find that the implementation of curricular and extracurricular outreach activities is correlated with an increased sense of responsibility for public engagement on the topic of climate change. This is supported by the fact that $100 \%$ of the surveyed upperclassmen stated that they somewhat or strongly agreed with the statement, "I think it is important for scientists to communicate the science of global warming to the public" (Fig. 1d).

When asked about their own climate change communication, only $29 \%$ of students reported talking about global warming with family and friends at least occasionally before they came to Lyndon (22\% of current upperclassmen and $44 \%$ of current first-year students; Fig. 2a). However, 78\% of upperclassmen stated that they now discuss it at least occasionally with people outside the ATM department (the question was modified from the first to focus on informal discussions outside of academia). It is particularly notable that $0 \%$ of upperclassmen stated that they never discuss it outside of the department.

LESSONS LEARNED. We have taken a multipronged approach by embedding anthropogenic climate change into the core curriculum, thus targeting all atmospheric sciences students regardless of career pathway, and providing various optional extracurricular opportunities for students who wish to engage at a deeper level. While climate change outreach efforts may take many forms (Fig. 3), we identify here a few key components which we believe have been essential for success.
Faculty buy-in and participation in extracurricular events is crucial. When faculty speak at public events, post about the science on social media, and publicly renounce statements that counter the science, we are setting examples for upcoming scientists. We further find that outreach activities work best when organized and facilitated by department faculty, particularly so they can assist as needed during the occasional confrontation by community members. To this end, it is important to acknowledge the tremendous amount of courage it takes to speak publicly about a topic that has become political and divisive. We must show continued support for our students as they navigate this new world. The latter can take the form of departmental news posts highlighting outreach activities, creating low-risk opportunities for students to speak at public events (i.e., panels moderated by someone who is more experienced), and providing supportive comments on students' social media posts.

Exposure to climate change concepts can influence student interest. Student responses to the initial curricular changes at Lyndon were not always favorable, with a few upperclassmen vocalizing their disapproval of the new required sophomore-level course. Our experience of a department-wide shift in student perceptions within just a couple of years, however, should empower faculty and administrators who are promoting similar curriculum changes, particularly in the face of student resistance.

Activities geared toward activism (i.e., climate marches) do not typically fall within the realm of scientific outreach, but are important nonetheless. The harsh reality of climate change can be overwhelming for some students, resulting in a sense of helplessness and

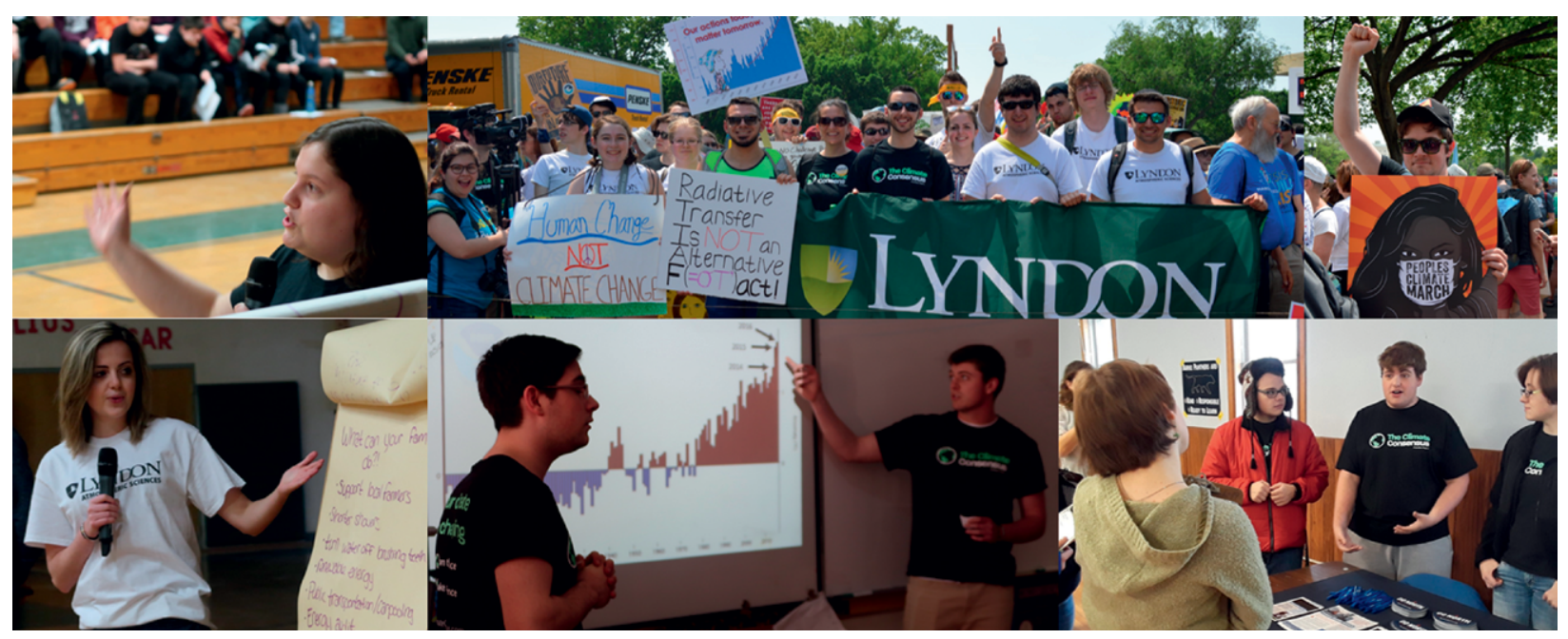

FIG. 3. Lyndon ATM students engaging in climate change outreach activities. 
isolation. After engaging in group activism, students have expressed more optimism about the possibility of meaningful climate change mitigation, often motivating them to find additional outreach opportunities. In addition to boosting group morale, such activities have garnered attention from the campus community, students and faculty alike, all of which has been positive.

SUMMARY. The Atmospheric Sciences Department at Northern Vermont University-Lyndon has successfully implemented curricular and extracurricular activities designed to improve students' climate change literacy and to promote outreach. To increase knowledge, all ATM students regardless of career pathway are required to take courses that cover the science of human-caused climate change. As a result, an increasing number of students are expressing interest, with several even selecting internships and career paths with connections to climate change. To promote outreach, students are creating informational content for a department-run website and are regularly given opportunities to engage face-to-face with the public at local schools and events. As a result of these efforts, students are expressing a heightened sense of responsibility to convey accurate climate change information to the public, and many have sought opportunities to engage in this work.

The model discussed here incorporates methods for improving climate change literacy among upcoming atmospheric scientists and raising awareness about the need for public engagement. This is an important step toward improved communication between experts and nonexperts, but ongoing work involves the integration of best practices as identified in the existing climate change communication literature (i.e., Leiserowitz et al. 2018). Our goal is to promote engagements that are increasingly positive and impactful, thus ultimately improving literacy among the general public and moving us one step closer toward meaningful climate change mitigation.

ACKNOWLEDGMENTS. The authors thank Jason Kaiser, David Siuta, Ari Preston, George Loriot, and Dawn Kopacz for productive conversations and helpful feedback. We would also like to thank faculty and staff at Lyndon for their continued support of our efforts, and former and current Lyndon ATM students who have demonstrated courage by speaking out about the science, especially Arianna Varuolo-Clarke and Kayla St. Germain, who prompted the creation of The Climate Consensus group.

\section{FOR FURTHER READING}

Biermann, F., and I. Boas, 2010: Preparing for a warmer world: Towards a global governance system to protect climate refugees. Global Environ. Polit., 10, 60-88, https://doi.org/10.1162/glep.2010.10.1.60.

Ding, D., E. W. Maibach, X. Zhao, C. Roser-Renouf, and A. Leiserowitz, 2011: Support for climate policy and societal action are linked to perceptions about scientific agreement. Nat. Climate Change, 1, 462-466, https://doi.org/10.1038/nclimate1295.

Hansen, J., and Coauthors, 2013: Assessing "dangerous climate change": Required reduction of carbon emissions to protect young people, future generations and nature. PLOS ONE, 8, e81648, https://doi .org/10.1371/journal.pone.0081648.

IPCC, 2013: Summary for policymakers. Climate Change 2013: The Physical Science Basis, T. F. Stocker et al., Eds., Cambridge University Press, 1-29.

Knutti, R., J. Rogelj, J. Sedláček, and E. M. Fischer, 2016: A scientific critique of the two-degree climate change target. Nat. Geosci., 9, 13-18, https://doi.org/10.1038 /ngeo2595.

Leiserowitz, A., E. Maibach, C. Roser-Renouf, S. Rosenthal, M. Cutler, and J. Kotcher, 2018: Climate change in the American mind: March 2018. Yale Project on Climate Change Communication, 53 pp., http://climatecommunication.yale.edu/publications /climate-change-american-mind-march-2018/.

Parmesan, C., and G. Yohe, 2003: A globally coherent fingerprint of climate change impacts across natural systems. Nature, 421, 37-42, https://doi.org/10.1038 /nature01286.

Roser-Renouf, C., E. Maibach, A. Leiserowitz, and S. Rosenthal, 2016: Global warming's six Americas and the election. Yale Program on Climate Change Communication, http://climatecommunication.yale.edu /publications/six-americas-2016-election/.

Urban, M. C., 2015: Accelerating extinction risk from climate change. Science, 348, 571-573, https://doi .org/10.1126/science.aaa4984.

USGCRP, 2017: Climate Science Special Report: Fourth National Climate Assessment, Volume I. D. J. Wuebbles et al., Eds., U.S. Global Change Research Program, 470 pp., https://doi.org/10.7930 /J0J964J6.

Wheeler, T., and J. von Braun, 2013: Climate change impacts on global food security. Science, 341, 508-513, https://doi.org/10.1126/science.1239402. 